\title{
One Cycle in-situ Processing of Nanoparticle- loaded Superparamagnetic Cellulose Fibers
}

\author{
M. Sh. Khalii ${ }^{\text {* }}$, M. L. Hassan ${ }^{\text {b,c }}$, and A. F. Ali ${ }^{\mathrm{a}, \mathrm{c}}$ \\ ${ }^{a}$ Inorganic Chemistry Dept., ${ }^{b}$ Paper and Cellulose Dept. and \\ ${ }^{c}$ Center of Excellence, National Research Center, Cairo, \\ Egypt.
}

\begin{abstract}
B AGASSE fiber suspensions, obtained from the Egyptian sugar B cane plants are used through one cycle of an in-situ processing to obtain superparamagnetic papers, bearing 5-13 wt\% ferrite nanoparticles of iron oxide or mixed oxides of iron with cobalt and/or nickel. Oxidation of metal hydroxides, precipitated by alkali from metal chlorides and nitrates were oxidized using hydrogen peroxide. The products' properties of the magnetic paper formed were evaluated by characterization using XRD, TEM, and magnetic hysteresis measurements. Although a one-cycle process was used, the process yielded magnetic fibers containing nanoparticles of about 30$80 \mathrm{~nm}$. Magnetic hysteresis-loops show that all products are superparamagnetic with relatively high saturation values.
\end{abstract}

Keywords: Cellulose, in-situ, and Magnetic nanoparticles .

Magnetically responsive cellulose fibers allow the investigation of new concepts in papermaking and packaging, security paper, and information storage. Potential applications are in electromagnetic shielding, magneto graphic printing, and magnetic filtering ${ }^{(1-5)}$. Ferrites are widely used for encoding information in the production of magnetic recording and storage media. They are used in the form of a thin layer on a plastic substrate for making diskettes or encoding of information on subway tickets in the form of a thin magnetic strip coated on the cardboard stock. The magnetic properties are an added value to the traditional characteristics of paper, making it an attractive objective in such diverse fields as recording media, novel handling systems and security paper uses.

Magnetic cellulose fibers can be prepared either by lumen loading or by insitu synthesis of ferrites. By using the lumen-loading technology, commercially available magnetic pigments can be introduced into the lumens of soft wood fibers from which magnetic paper may be prepared. Lumen loading of pulp fibers with commercial ferrites makes the cellulose fibers themselves magnetically responsive ${ }^{(5)}$. This allows filler ferrite particles to be introduced

*Corresponding author, Email address: mshkhali182@yahoo.com 
exclusively into the lumens of wood fibers while leaving the external surfaces free of filler. Lumen-loaded fibers act as magnetic dipoles allowing manipulation of fiber orientation in papermaking ${ }^{(5,6)}$.

Through the in-situ processing of magnetic paper, magnetic particles are prepared in presence of suspensions of suitable natural cellulose fibers via careful oxidation of ferrous hydroxide precipitated with $\mathrm{NaOH}$ from the ferrous ions ${ }^{(5,6-10)}$. This process gives rise to the formation of ferrite particles associated with, or inside, the cellulose fibers and takes advantage of the paper pulp's property of associating cations. But, at the same time, the presence of a suspension of cellulose fibers imposes restrictions on the method like the need to work at a $\mathrm{pH}$ of $<7$ and the fact that ferrite particles and the temperature range where the aqueous suspension is stable ${ }^{(11)}$ to obtain; small particle sizes, better dispersion and greater uniformity ${ }^{(12)}$. Starting with an iron solution usually leads to the formation of superparamagnetic magnetite or maghemite with very low coercive force $\left(\mathrm{H}_{\mathrm{e}}\right)^{(7-11)}$.

Superparamagnetically responsive fibers have smaller and less-colored pigments, which are only magnetic in the presence of a field. This excludes their use in magnetic recording applications but in biotechnology as magnetic separators of specific bio-molecules from mixtures (like antibody separations). To improve the magnetic properties of magnetic papers prepared by the in-situ approach, either the synthesis step is cyclically repeated over the previously formed particles ${ }^{(13)}$ or other cations are introduced into the system to form magnetic phases with higher anisotropy and higher coercive values ${ }^{(14-17)}$.

In general, the 'lumen-loading' approach is necessary to diminish the loss of mechanical strength of the fibers, and the poor retention of the inorganic particles ${ }^{(6-8)}$, while the 'in situ' approach offers greater control of both the magnetic properties and the variety of magnetic particles that can be incorporated into the final product ${ }^{(3)}$. Hence, superparamagnetic papers are obtained better through 'in situ' synthesis of ferrites ${ }^{(5-9,18)}$.

In the present work, we used $\mathrm{Co}^{2+}$ and/or $\mathrm{Ni}^{2+}$ mixed with $\mathrm{Fe}^{2+}$ and paper pulp suspensions obtained from the Egyptian sugar cane plants (bagasse fibers) in the in-situ processing to obtain, nanometer ferrites, super-paramagnetic papers of pure or mixed oxides. The formed particles properties are then evaluated.

\section{Experimental}

Materials

The source of cellulose fibers in this study was the unbleached bagasse pulp kindly supplied by Edfu Company for Pulp and Paper obtained from the Egyptian sugar can plants. The bulb was repeatedly washed with distilled water, filtered, and then soaked overnight in distilled water. Reagent grade chemicals were used $\mathrm{FeCl}_{2} \cdot 4 \mathrm{H}_{2} \mathrm{O}, \mathrm{Co}\left(\mathrm{NO}_{3}\right)_{3} \cdot 6 \mathrm{H}_{2} \mathrm{O}$ (AR-grad), and $\mathrm{NiCl}_{2} \cdot 3 \mathrm{H}_{2} \mathrm{O}$; all from 
Aldrich Chemical Co. $\mathrm{NaOH}$ pellets and hydrogen peroxide from Merck, Germany. Suspensions of bagasse and solutions of metal salts were prepared with distilled water.

\section{Method}

Approximately $3 \mathrm{wt} \%$ suspension of the cellulose bulb fibers was vigorously stirred for $2 \mathrm{hr}$. Meanwhile, salts of iron, nickel, and cobalt were dissolved into bi-distilled water to obtain 0.45 molar solutions of iron or the mixed metal solutions shown in the coming table.

In each experiment, a half a liter portion of the cellulose fiber suspension was mechanically agitated in a 1 liter beaker placed into a water bath at $70{ }^{\circ} \mathrm{C}$ while $250 \mathrm{ml}$ of one of the metal solutions was added. The final metal ion concentrations in the different suspensions were thus about $0.15 \mathrm{~mol} / \mathrm{L}$ of iron (sample F), iron/nickel (sample FN), iron/cobalt (sample FC), and iron/cobalt/nickel (sample FNC). Mechanical agitation was continued for $1 \mathrm{hr}$ for the ionic exchange to occur. A stoichiometric amount of $0.5 \mathrm{M} \mathrm{NaOH}$ solution was then added dropwise, from a burette, to each suspension where dark green to dirty black suspensions were immediately formed ${ }^{(3,16)}$. As the particle size of the formed precipitate is dependant on the concentration of the precursor solution and on the rate of precipitation ${ }^{(3)}$, concentration of the precursor solutions used and the precipitation rate were aimed to form nanosized precipitates. The suspensions were then heated to $65{ }^{\circ} \mathrm{C}$ in a water bath and hydrogen peroxide solution $(3 \%$ ) was added dropwise with constant stirring over a period of $20 \mathrm{~min}$ for full oxidation ${ }^{(5)}$. Hydrogen peroxide was added in a small excess than the stoichiometric ratio for oxidation.

Each fiber suspension was then repeatedly decanted in fresh bi-distilled water to get rid of sodium salts and the excess particles and outer surface of the fibers was washed by repeated filtering and suspension in water. Each fiber sample was then taken for characterization and the fibers were again stirred in distilled water. Paper sheets were formed by filtering the final suspension and drying the pulp pad overnight in a press with heating plates at $105{ }^{\circ} \mathrm{C}$ and 40 atm.

For comparison, stoichiometric volumes of $\mathrm{NaOH}$ solution were also added, from a burette, to each of the iron chloride solution and the mixed solutions of metal salts following the same procedure above but in absence of cellulose fiber.

\section{Characterization}

The magnetic cellulose fibers and particles produced were characterized by a number of methods. X-ray diffraction patterns were recorded in the $2 \theta$ range of $25-70^{\circ}$ using an X-ray diffractometer, model BRUKER axis, D8ADVANCE employing a Ni-filtered $\mathrm{Cu} \mathrm{K \alpha}$ irradiation (wavelength $0.154 \mathrm{~nm}$ ), operated at $40 \mathrm{kV}$ and $30 \mathrm{~mA}$. 
The magnetic nanoparticles and the loaded fibers were analyzed by transmission electron microscopy (TEM) and selected area electron diffraction pattern (SAD) were carried out using a JEOL 1230 transmission electron microscope (Japan) with acceleration voltage $100 \mathrm{KV}$. A drop of fiber suspension was used on a copper grid bearing a carbon film.

Hysteresis loops were measured using a computerized vibrating sample magnetometer (VSM) for weighed (10-15 mg) pulp samples with their surface parallel to the horizontally applied DC magnetic field. The sample vibrates vertically and the dipole field of the sample induces an AC signal in a pair of detection coils, which is proportional to the magnetization of the sample.

Product samples were oven-dried at $110^{\circ} \mathrm{C}$ overnight and their ash content was determined after combustion at $900{ }^{\circ} \mathrm{C}$ for $5 \mathrm{hr}$.

\section{Results and Discussion}

The X-ray diffraction pattern of nanoparticles separately synthesized in the same conditions as sample F, (using only iron salt), but in absence of the cellulose fibers is shown in Fig. 1. The pattern shows a major phase of $\mathrm{Fe}_{3} \mathrm{O}_{4}$ as listed in ASTM XRD standard card (19-0629). X-ray broadening indicates products of particle sizes in the nanometer range ${ }^{(3,19)}$ in the experimental conditions of work.

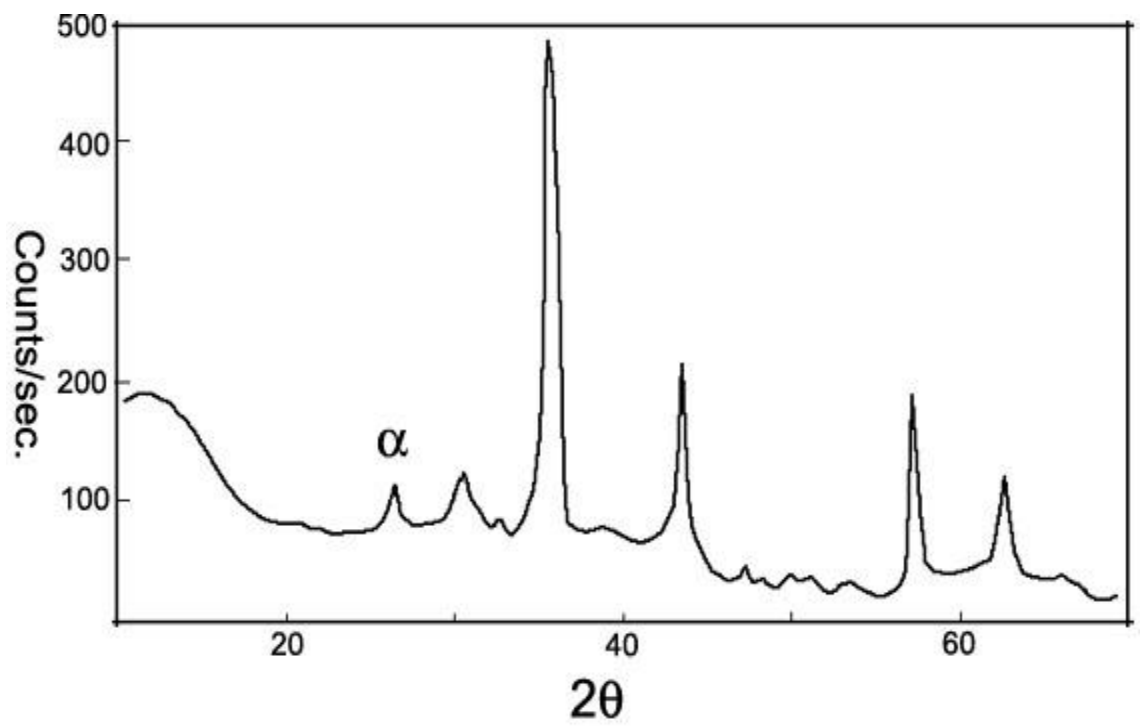

Fig. 1. XRD pattern of $\mathrm{Fe}_{3} \mathrm{O}_{4}$ nanoparticles separately synthesized in the same conditions as other samples but in absence of the cellulose fibers. $\alpha$ is the $\alpha-\mathrm{FeOOH}$ phase. 
Figure 2 shows the XRD patterns of different magnetic cellulose fibers as loaded with iron oxide (F), mixed iron-cobalt oxides (FC), iron-nickel oxides $(\mathrm{FN})$, and iron-cobalt-nickel oxides (FCN). In presence of cellulose, the patterns are some complicated but still show the typical peaks of crystalline ferrites ${ }^{(1)}$. This is supported by the selected area electron diffraction patterns (SAD) of the loaded fibers of samples FC and FCN shown in Fig. 3. It is thus clear from these figures that, under the stated experimental conditions, magnetic cellulose fibers loaded with crystals of pure or mixed ferrites of the specified cations could be obtained by full oxidation of the alkali-precipitated hydroxides using hydrogen peroxide leading to ferrite forms ${ }^{(20,21)}$. A detailed mechanistic process for crystal formation and growth has been proposed elsewhere ${ }^{(10,22)}$.

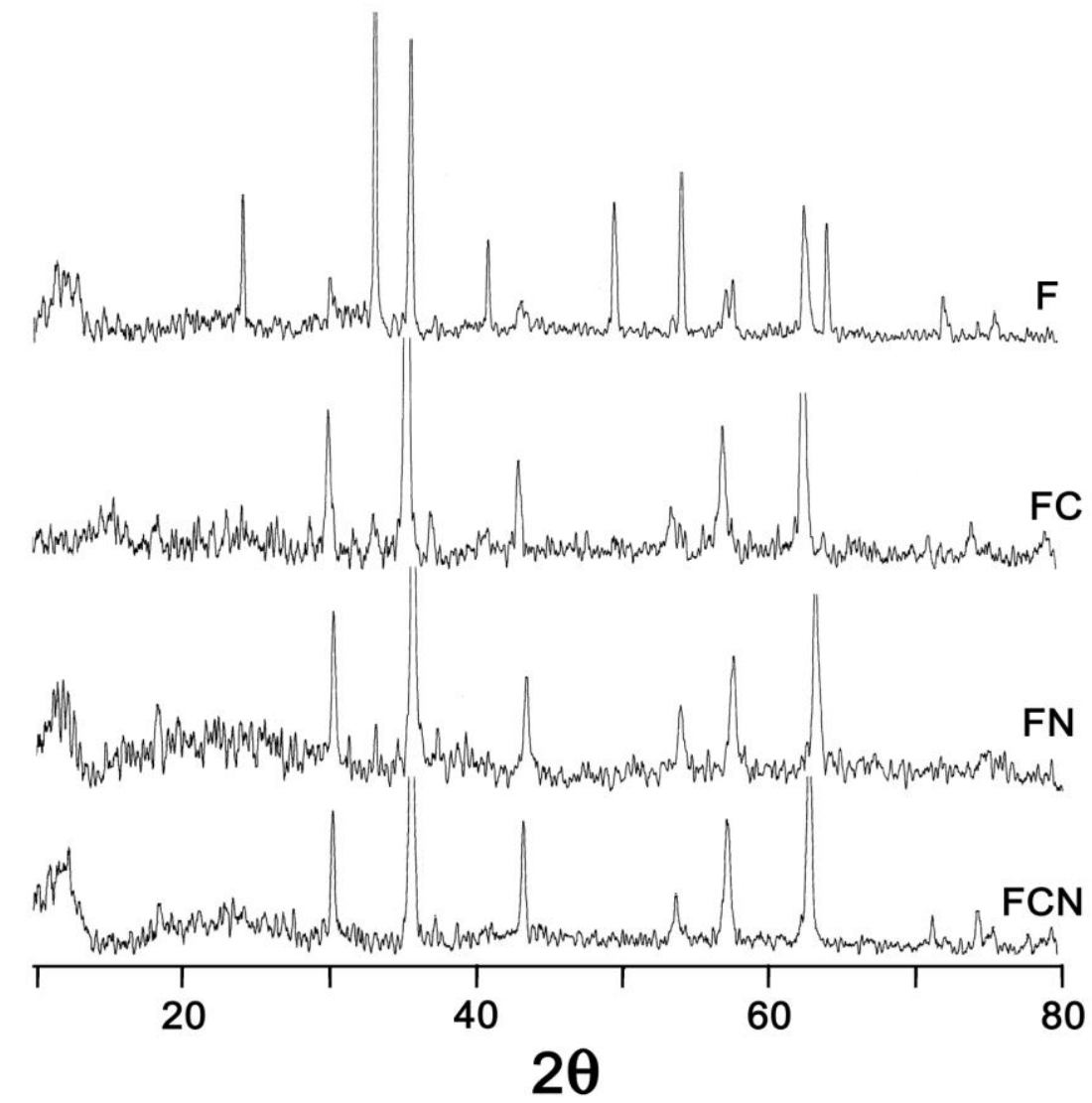

Fig. 2. XRD patterns of different cellulose fibers loaded with iron oxide (F), mixed iron-cobalt oxides (FC), iron-nickel oxides (FN), and iron-cobalt-nickel oxides (FCN). 

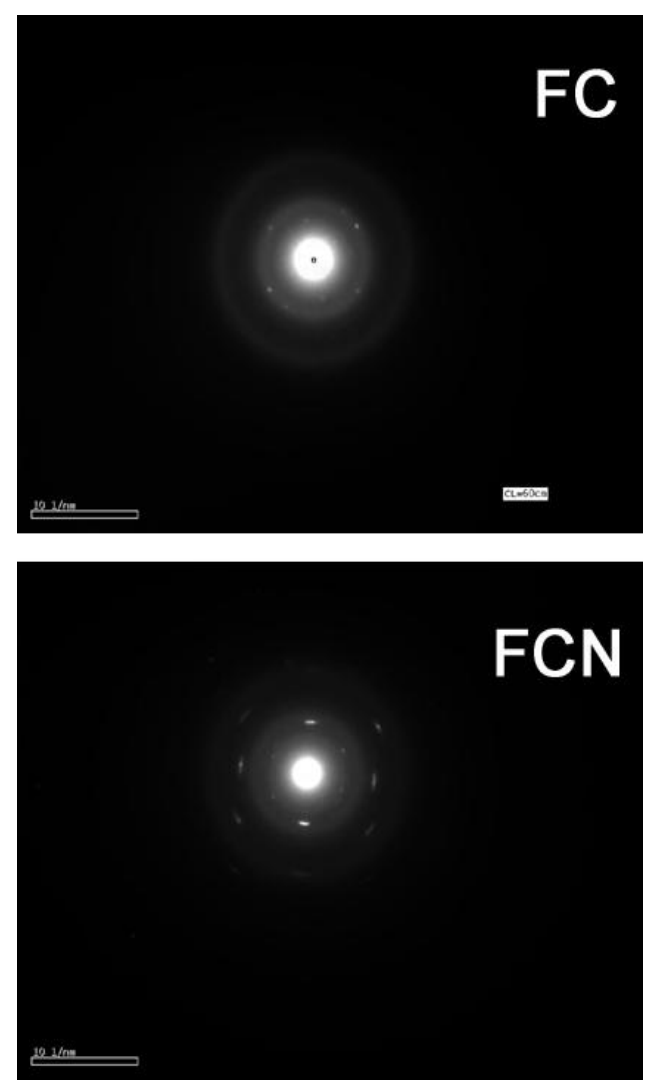

Fig. 3. Selected area electron diffraction patterns (SAD) of loaded fibers of samples FC and FCN.

The results of ash content measurements are shown in the table. The differences between the loading efficiencies may arise from the difference in grain size of the different ferrites incorporated into the fibers as smaller grains will, of course, pack easier into the available lumens and pores. In general, the process followed in this study enabled a reasonable loading efficiency of all the prepared samples.

\begin{tabular}{lcc}
\hline Sample & Cation used & Ash content, $\%$ \\
\hline F & $\mathrm{Fe}^{2+}$ & 12.52 \\
FC & $\mathrm{Fe}^{2+} / \mathrm{Co}^{3+}$ & 8.50 \\
FN & $\mathrm{Fe}^{2+} / \mathrm{Ni}^{2+}$ & 5.4 \\
FCN & $\mathrm{Fe}^{2+} / \mathrm{Co}^{3+} / \mathrm{Ni}^{2+}$ & 5.9 \\
\hline
\end{tabular}


For the morphology and average particle sizes of the ferrites prepared in this work, Fig. 4 shows the transmission electron micrographs (TEM) of the oxide powders obtained from metal salt solutions in absence of cellulose fibers. An average size of about 30 to $80 \mathrm{~nm}$ well-dispersed particles can be noticed. This average particle size is relatively larger than that reported by other investigators who suggested performing repeated cycles of reaction on the fiber suspension to obtain crystals of such a large particle size ${ }^{(10)}$.
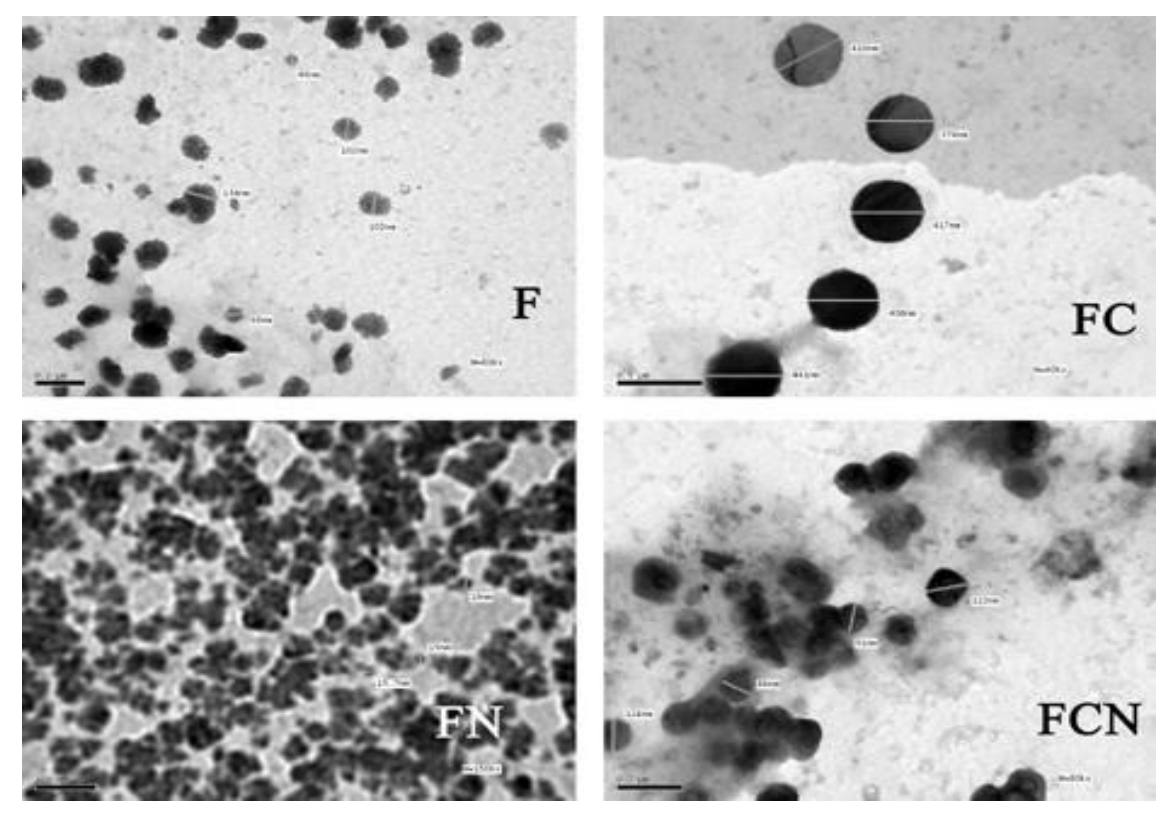

Fig. 4. TEM images of oxide powders obtained from metal salt solutions in absence of cellulose fibers.

F, FC, FN, and FCN refer to oxide powders obtained from solutions of iron, iron/cobalt, iron/nickel, and iron/cobalt/nickel salt, respectively.

Figure 5 shows the TEM images of iron oxide-loaded cellulose fiber, (sample F). It is clear that the lumen is homogeneously loaded with the ferrite particles with some crystals on the outer surface ${ }^{(18)}$. Both Fig. $4 \& 5$ show filler nanoparticles of almost spherical shape. Products of other shapes (plate-like, needle, acicular, equiaxial) were obtained by other investigators ${ }^{(10,22,23)}$.

Compared to the lumen loading method, the size and distribution of the magnetic particles are more even for the in-situ synthesis. In the in-situ synthesis method, magnetite particles are formed on the spot inside the lumen of fibers once $\mathrm{NaOH}$ was added. During the initial stage, the iron salt was dissolved and $\mathrm{Fe}^{2+}$ penetrated homogenously inside the lumen of the fibers by vigorous stirring with mechanical stirrer, thus leading to the better particle distribution ${ }^{(3)}$. 

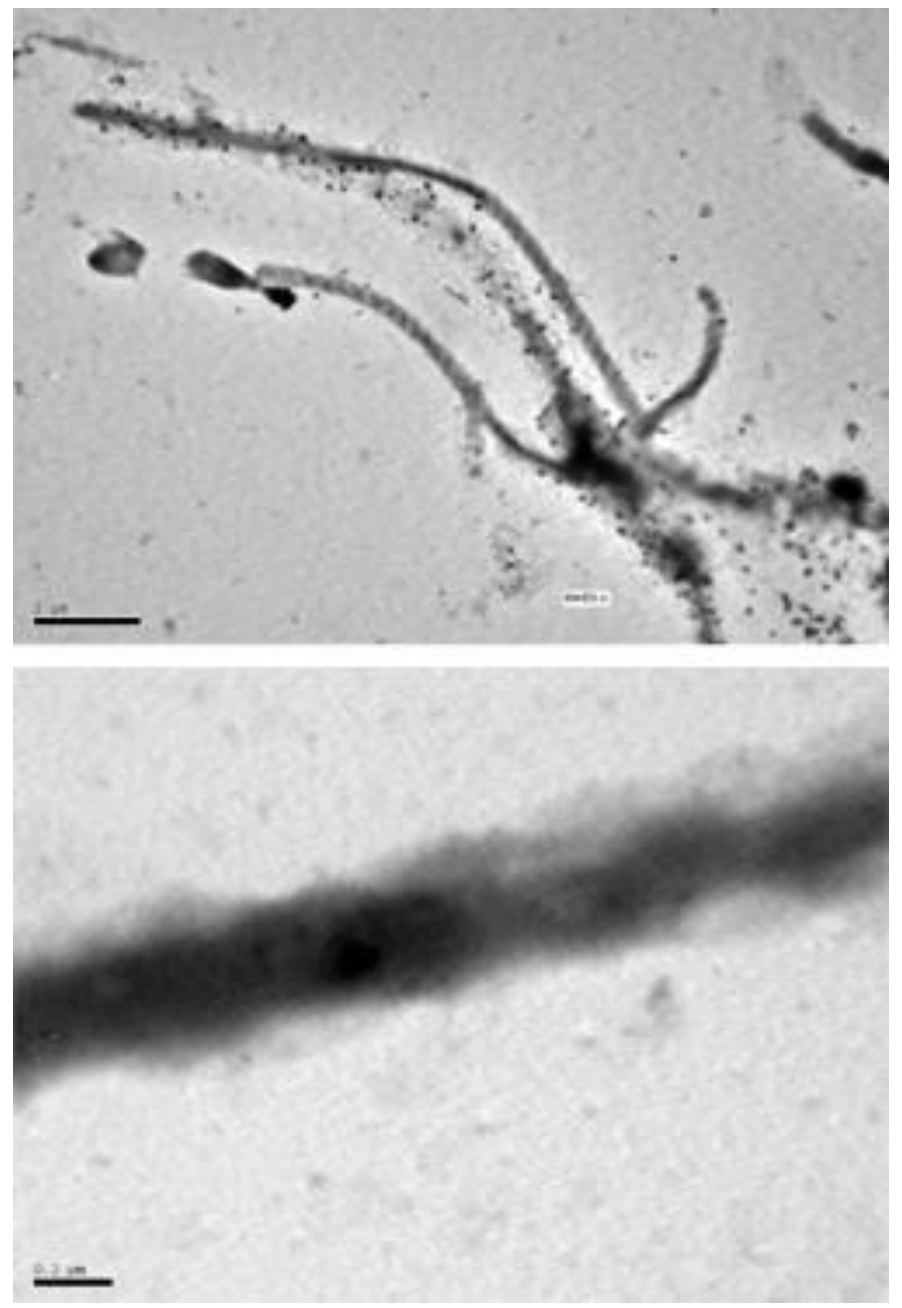

Fig.5. TEM of iron oxide loaded cellulose fiber, (sample F).

Figure 6 shows the magnetic hysteresis loops obtained for the loaded fibers at $300{ }^{\circ} \mathrm{K}$ plotting the specific magnetization as a function of the applied filed. For all samples, the typical S-shaped curve or the hysteresis loop passes directly through the origin, indicating that these materials are superparamagnetic $\left.{ }^{(10,12,23-25}\right)$. That is, they do not display the remenance and coercivity phenomena characteristic of commercial ferrites used in information-storage applications. This factor is attributed to the small sizes of the in-situ synthesized particles, which is also responsible for the relatively light-brown color as compared to commercial synthetic magnetite particles which are 10-100 times larger ${ }^{(10)}$. 


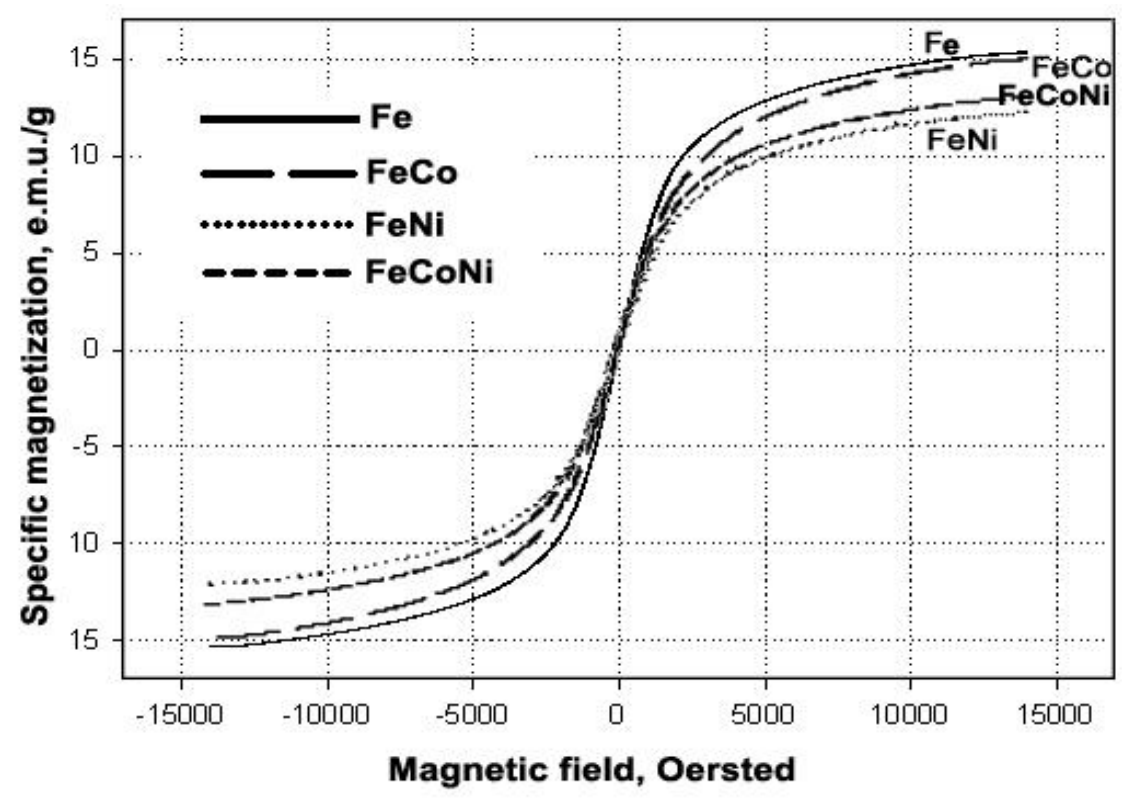

Fig. 6. Magnetic hysteresis loops for the loaded fibers at $300{ }^{\circ} \mathrm{K}$.

Figure 7 shows how the fibers of sample $\mathrm{F}$ were magnetically responding to the magnetic field produced by the electron beam while being subject to TEM micrography.

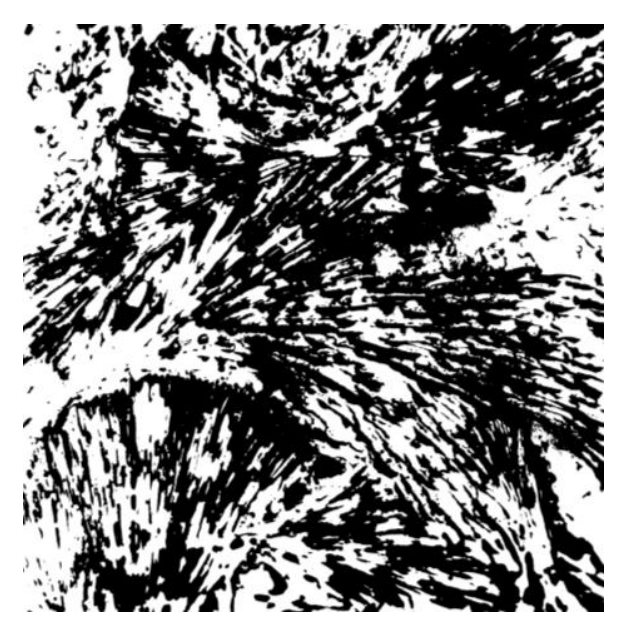

Fig. 7. Transmission electron micrograph (TEM) of fibers of sample F.

Egypt. J. Chem. 55, No. 4 (2012) 


\section{Conclusion}

A one-cycle in-situ process could be followed to obtain superparamagnetic cellulose fibers of reasonable loading with nanoparticle ferrites as iron oxide or mixed oxides, iron with cobalt and/or nickel using bagasse fibers and metal salts. Oxidation of metal hydroxides, precipitated by alkali from metal chlorides and nitrate using hydrogen peroxide could lead to products of superparamagnetic behavior. The experimental conditions provided in this work, produced superparamagnetic fibers without repeating the loading cycle as necessitated by previous studies ${ }^{(1,11)}$. The product samples showed uniform spherical filler nanoparticles of about 30-80 $\mathrm{nm}$ and relatively high saturation values.

\section{References}

1. Munawar, R. F., Zakaria, S., Radiman, S., Chia, C. H., Abdullah, M. and Yamauchi, T., Properties of magnetic paper prepared via in situ synthesis method. Sains Malaysiana, 39 (4), 593 (2010).

2. Chia, C. H., Zakaria, S., Nguyen, K. L., Dang, V. Q. and Duong, T. D., Size and crystallinity dependent magnetic papers. Materials Chemistry and Physics, 113, 768 (2009).

3. Small, A.C. and Johnston, J.H., Nouvel hybrid materials of magnetic nanoparticles and cellulose fibers . Journal of Collids and Interface Sci. 331,122 (2009).

4. Chia, C.H., Zakaria, S., Abdullah, M. and Jani, S. M., Preparation of magnetic paper from kenaf. Am. J. Appl. Sci. 3(3), 1750 (2006).

5. Marchessault, R.H., Rioux, P. and Louis, R., Electromagnetic shielding, magnetographic printing and magnetic filtering. Polymer, 33(19), 4024 (1992).

6. Zakaria, S., Ong, B.H. and Van de Ven, T.G. M., Lumen loading magnetic paper I : Flocculation strength of fibers. Colloid and Surfaces A, Physicochemical and Engineering Aspects, 251, 1-4 (2004).

7. Idem, II : Mechanism and Kinetics, 251, 31 (2004).

8. Middleton, S.R. and Scallan, A.M., Effect of addition of cationic polyacrylamide to the pulp lumen loading. J. Pulp pap. Sci. 15, J229 (1989).

9. Raymond, L., Revol, J. F., Ryan, D. H. and Marchessault, R. H., Synthesis and characterization of an iron oxide polystrene complex. Chem. Materials, 6, 249 (1994).

10. Marchessault, R. H., Recard, S. and Rioux, P., In situ synthesis of ferrite in lignocellulosics. Carbohydrate Res. 224, 133 (1992). 
11. Carazana-Garcia, J.A. and Lopez-Cuintela, M.A., Rivas-ray, Investigation of polymer magnetic microsphere of ferrite particles. Colloid and Surfaces A, Physicochemical and Engineering Aspects, 121, 61 (1997).

12. Ziolo, R.F., Synthesis of alginic acid- $\mathrm{Fe}_{3} \mathrm{O}_{4}$ nano-composite. US Patent, 4474866, (1984) Chem. Abst. 2 (15),114 (1985).

13. Serge, R. and Marchessault, R.H., Preparations in situ magnetically loaded cellulose fibers. Mat. Res. Symp. Proc., Materials R. Soc. 197, 319 (1990).

14. Sobon, C. A., Bowen, H. K., Broad, A. and Calvert, P. D., Mater. Sci. Left . 8, 901 (1987).

15. Calvert, P. D. and Mann, S., Crystallization of an inorg. phase controlled by a polymermatrix. Mat. Sci. 11, 3801 (1988).

16. Cao, Z., Nano Structures and Nano Materials, Synthesis and Properties. Imperial College Press, 15 (2004).

17. Berger, P., Adelman, N.B., Beckman, K.J., Campbell, D.J., Ellis, A.B. and Lisensky, G.C., Preparation and properties of an aqueous ferrofluids. J. Chem. Ed. 76, 943 (1999).

18. Carazana-Garcia, J.A. and Lopez-Cuintela, M.A., Rivas-ray, Ferrimagnetic paper obtained by in situ synthesis of substituted ferrites. J., IEEE Tranc. Mag. 31, 3126 (1995).

19. Thapa, D.. Palkar, V.R.. Kurup, M.B. and Malik, S.K., Faraday rotation in magnetite structure magnetic properties and mossbauer spectra of $\mathrm{LaSrFeMnO}_{3}$. Mater. Lett. 58, 2692 (2004).

20. ASTM E112-88, Annual Book of ASTM Standards, Philadelphia, PA, pp. 284 (1988).

21. ASTM E562-83, Annual Book of ASTM Standards, Philadelphia, PA, pp. 612 (1983).

22. Sugimoto, T. and Matijvic, E., Morphological transformation of $\mathrm{Fe}_{3} \mathrm{O}_{4}$ spherical aggregates. J. Colloid interface Sci. 74, 227 (1980).

23. Sourty, E., Rayan, D.H. and Marchessault, R.H., Characterization of magnetic membranes based on bacterial and man-made cellulose. Celulose, 5, 5 (1998).

24. Raymond, L., Revol, J.F., Marchessault, R.H. and Ryan, D.H., In situ synthesis of ferrites in ionic and neutral cellulose gels. Polymer, 36 (26), 5035 (1995).

25. Goss, G., Rapid mixing : A route to synthesize magnetite monoparticles with high moment. J.Phys. Chem. Min. 164 (1988).

(Received 10/9/2012; accepted 15/10/2012)

Egypt. J. Chem. 55, No. 4 (2012) 


\title{
تحميل النسخة السيليلوزيه بمادة نانومترية فائقة المغناطيسية

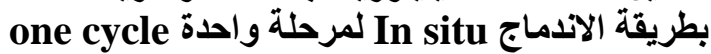

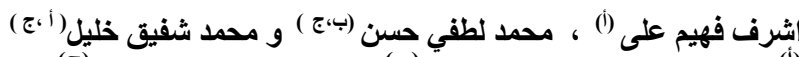

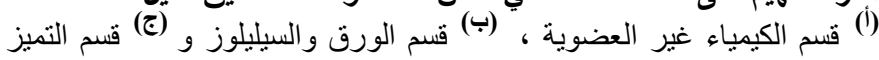

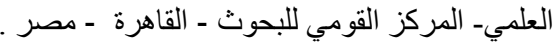

استخدم مستحلب ومعلق نسيج مصاصة نبات القصب المصري لمرحلة واحدة

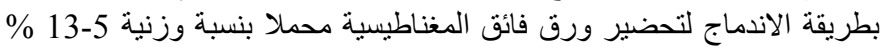

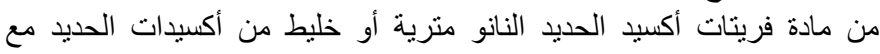

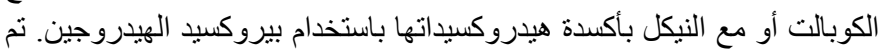

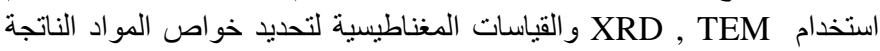

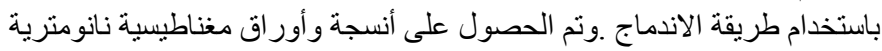

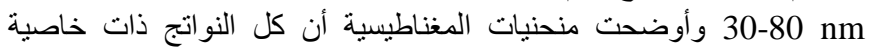

مغناطيسية فائقة القيمة. 